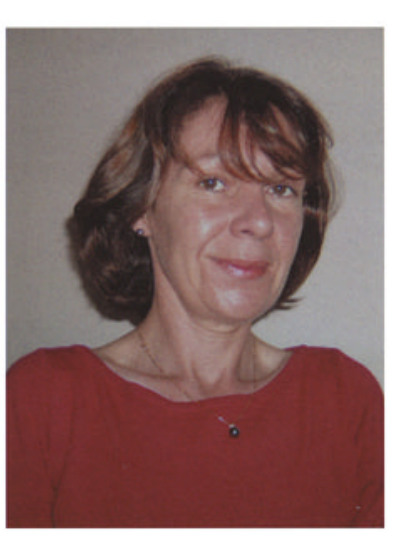

Par Martine Pasquet-Février, Hopital notre-Dame de bon Secours, 75014, PARIS

\section{"Elle concerne chaque} année plus de 800000 femmes en France et la quasi-totalité des biologistes est impliquee.e."

\title{
Exploration biologique de la grossesse
}

La surveillance biologique de la femme enceinte, le dépistage, le diagnostic et la prise en charge des pathologies maternelles et foetales sont des sujets pluridisciplinaires en constante évolution et à la pointe de l'actualité. Elle concerne chaque année plus de 800000 femmes en France et la quasi-totalité des biologistes est impliquée. Retenir les pathologies à dépister (selon leur gravité, les traitements disponibles et la prise en charge), définir les populations concernées (dépistage systématique ou ciblé), affiner et adapter les outils disponibles et en évaluer les résultats sont les enjeux de l'efficacité de cette surveillance. Les examens de surveillance obligatoires sont définis par l'arrêté du 19.04.1985 complété par le décret du 14.02.1992. La loi du 27.01.1993 rend obligatoire de proposer le dépistage de l'infection par le ViH. Depuis janvier 1997 est proposé et pris en charge le dépistage de la trisomie 21. La surveillance biologique de la femme enceinte fait l'objet de plusieurs recommandations ANAES (1995-1996-2001). Le diagnostic et la surveillance des pathologies à risque permettent d'assurer leur prise en charge en fonction de l'état de l'art. Ce dossier propose:

- une revue des stratégies diagnostiques des infections (virales et parasitaires) maternelles à risque de transmission fotale que l'on pourra compléter (pour les infections bactériennes) par les recommandations ANAES sur la prévention anténatale du risque infectieux bactérien néonatal précoce (2001);

- des modalités pour le dépistage du diabète gestationnel selon les recommandations disponibles;

- un rappel sur l'organisation de la surveillance biologique de l'HTA gravidique et de ses complications à haut risque ;

- des recommandations pour le suivi immuno-hématologique de la grossesse dont on peut attendre une évolution, en raison des progrès de l'étude de l'ADN fœtal dans le sang maternel par PCR en temps réel;

- les indications de l'analyse de l'ADN foetal dans le sang maternel;

- une évaluation de la stratégie actuelle du dépistage de la trisomie 21 ;

- les évolutions du diagnostic prénatal des maladies héréditaires du métabolisme dont certaines deviennent traitables et d'autres accessibles au diagnostic prénatal permettant une prise en charge et une information précoces des parents. L'initiative de la rédaction de mettre ce dossier à la tribune des biologistes pour concourir à une meilleure prise en charge de la prérinatalité doit être saluée. 